\title{
29 ADDRESSING THE SHORTCOMINGS OF INTERPRETIVE FIELD RESEARCH: REFLECTING SOCIAL CONSTRUCTION IN THE WRITE-UP
}

\author{
Ulrike Schultze \\ Southern Methodist University \\ U.S.A.
}

\author{
Michael D. Myers \\ University of Auckland \\ New Zealand
}

\author{
Eileen M. Trauth \\ Northeastern University \\ U.S.A.
}

\begin{abstract}
Recent critical discussion of interpretive field research suggests that there exist two major concerns with the state of the art use of interpretive field methods in Information Systems. First, many interpretive researchers pay insufficient attention to critical reflection on how the research materials were socially constructed through interaction between the researchers and the participants in their field studies. Second, it appears that the preferred pattern for interpreting field data is to begin with an a priori theory. This raises concerns not only about unwarranted theoretical bias in researchers' interpretations, but also about the researcher's propensity to question his/her assumptions in the process of making sense of the data. The implication of these two shortcomings is that "we are given little understanding of how the researchers' analysis developed over the course of the project. As it stands, we are presented with a finished piece of interpretive research with few
\end{abstract}

The original version of this chapter was revised: The copyright line was incorrect. This has been corrected. The Erratum to this chapter is available at DOI: 10.1007/978-0-387-35505-4_33 
indications of its emergent nature" (Klein and Myers 1999, p. 25). The IS community is thus not given enough insight into how interpretive researchers resolve the contradictions between the theoretical preconceptions guiding their research and the results that are generated.

In this panel, we wish to explore how widespread these two shortcomings are in interpretive IS research, what accounts for their existence, whether they serve a purpose and how they can be remedied. Do the politics of publishing play a role in generating certain shortcomings in current interpretive field research? What does it take to give readers a better understanding of how the researcher and his/her analysis developed over the course of the research? Is it a problem that can be addressed by special methodological strategies and techniques and if so, by which? Or could it be that authors simply need to adopt a different style of writing up the research? What would such writing styles look like? Is the confessional style of writing (Van Maanen 1988; Trauth 1997; Schultze 1999) the only alternative? If so, what are the consequences of an author making him/herself vulnerable by including autobiographical details in his/her "scientific" writings? Can this style of writing be taught? How will it be viewed and received in different cultures?

These are the kinds of questions we wish to explore with the audience in this panel. We plan to proceed in the following way:

Ulrike Schultze will introduce the panel by outlining the motivation for the discussion about the challenge of living up to the expectation of high-quality interpretive research. She will then introduce the panel members' research and relate their expertise to the purpose of the panel. This should orient the audience to how each panel member will approach the questions and issues that the panel seeks to address.

Michael Myers will highlight some of the major shortcomings identified in interpretive field research in IS and the importance of correcting them. He will focus particularly on two shortcomings, namely the lack of critical reflection on how the research materials were socially constructed through interaction between the researcher and the participants, and the preference for theory-driven interpretation. He will then discuss how and why some of the principles that he advocated in Klein and Myers were not applied in the writing up of some of his earlier research work (e.g., Myers 1994). He will argue that it is possible to satisfy both shortcomings in interpretive IS research without necessarily adopting a confessional style of writing.

Eileen Trauth will discuss the same two shortcomings in interpretive IS research with respect to her own research and publishing experiences. Her own interpretive work places a priority on establishing a connection between the researcher and the participants in the field study. She will show how a data-driven (vs. a theory-driven) approach in conducting the research led her to a confessional style of writing the results. She will also discuss the political difficulties she had in trying to get interpretive work that is "in her own voice" published. She will raise questions about our own academic culture and its effect on the audience for self-reflexive writing. Finally, she will discuss the joys of conducting self-reflexive research and the liberation of the author through the more personalized styles of writing

Ulrike Schultze will explain how she addressed the same two shortcomings of interpretive IS research in her work. She will outline her use of a confessional genre of representation and the implications such a genre has for both the fieldwork and the 
subsequent deskwork. In contrast to Eileen Trauth, who will address the joys and liberation of self-revealing writing, Ulrike will focus on the concerns about professional identity that are related to writing in a confessional style.

Each panelist's presentation will be timed in such a way that at least 30 minutes remain at the end for the question and answer session and audience participation.

\section{References}

Klein, H. K., and Myers, M. D. “A Set of Principles for Conducting and Evaluating Interpretive Field Studies in Information Systems," MIS Quarterly (23:1), 1999, pp. 67-93.

Myers, M. D. "A Disaster for Everyone to See: An Interpretive Analysis of a Failed IS Project," Accounting, Management and Information Technologies (4:4), 1994, pp. 185-201.

Schultze, U. "A Confessional Account of an Ethnography about Knowledge Work," MIS Quarterly (forthcoming, 1999, electronic pre-print available at www.cox.smu.edu/ faculty/uschultz/research/).

Trauth, E. M. "Achieving the Research Goal with Qualitative Methods: Lessons Learned Along the Way," in Information Systems and Qualitative Research, A. S. Lee, J. Liebenau, and J. I. DeGross (eds.). London: Chapman and Hall, 1997, pp. 225-245.

Van Maanen, J. Tales of the Field: On Writing Ethnography. Chicago: University of Chicago Press, 1988.

\section{About the Panelists}

Ulrike Schultze is an assistant professor in the Information Systems and Operations Management Department at Southern Methodist University. Her research focuses on knowledge work, particularly informing practices, i.e., the social processes of creating and using information in organizations. Ulrike has written on hard and soft information genres, information overload, knowledge management and knowledge workers' informing practices. Her dissertation research, which was completed in Fall 1997, is an ethnographic field study of knowledge work. Her first publication from this study is written in a confessional genre of representation. Ulrike can be reached by e-mail atuschultz@mail.cox.smu.edu.

Michael D. Myers is an associate professor in the Department of Management Science and Information Systems at the University of Auckland, New Zealand. Michael has published widely in the areas of qualitative research methods, interpretive research, ethnography, and information systems implementation. He is editor of the ISWorld Section on Qualitative Research, an associate editor of MIS Quarterly, and an associate editor of Information Systems Journal. Michael can be reached by e-mail at m.myers@, auckland.ac.nz.

Eileen M. Trauth is an associate professor of Management Information Systems in the College of Business Administration at Northeastern University. Her research interests center around the cultural, societal, organizational, and educational impacts of information technology. She has published articles recently about the global information economy, information policy, IT education, and information management. Her research, which employs qualitative methods, is primarily directed at uncovering contextual influences and impacts on information technology and information professionals. While she has done research in several countries, her most extensive piece of qualitative work 
has been a multiyear, ethnographic investigation of socio-cultural influences on an emerging information economy. She has published several papers from this research and a forthcoming book about it is written in the confessional genre. Eileen can be reached by e-mail at trauth@neu.edu. 